\title{
Ethanol-induced response stereotypy: Simple alternation, fixed-interval rates of response, and response location
}

\author{
LOWELL T. CROW \\ Western Washington University, Bellingham, Washington 98225
}

\begin{abstract}
Three experiments, carried out to examine ethanol-induced response stereotypy, noted the rat's performance on a two-bar operant alternation task, on a fixed-interval 10-sec schedule of reinforcement, and on two-bar response-location variability. Low and moderate (.5-1.2 g/kg) doses reduced the number of errors in simple alternation, whereas higher doses $(1.5 \mathrm{~g} / \mathrm{kg})$ increased errors. The change in rate of responding (scallop) within the fixed interval of reinforcement was reduced by moderate doses, but no relationship was found between ethanol doses and response-location variability. The results are discussed as they relate to similar findings with alcohol and other drug treatments.
\end{abstract}

Recent studies have implicated ethanol with a decreased behavioral variability or stereotypy of responding (Crow, McWilliams, \& Ley, 1979; Crow, Westveer, \& Kass, 1976; Devenport, Merriman, \& Holloway, Note 1). The behavioral measures employed in these studies differ, ranging from the rat's performance in a radial arm maze to analyses of operant responses, but a common element of the alcohol effect, apart from sedation, and so on, is the apparent promotion of stereotypy (Devenport et al., Note 1).

A proposal for the general theory of amphetamineinduced stereotypy, proposed by Lyon and Robbins (1975), is of value to considerations of alcohol-induced stereotypy due to the vast amount of work carried out on that drug most closely associated with behavioral stereotypy. Rate dependency (Dews, 1958), for example, was seen by Lyon and Robbins (1975) as reduced behavioral variability as a result of amphetamine treatment, and as this effect has now been shown for alcohol as well (Leander, McMillian, \& Ellis, 1976), a similar argument may be made.

Separate from drug-behavior studies, but of use for this purpose, is a literature of behavior variability measures yet different from those above. For example, stereotypy has been defined by operant behavioral sequences in complex patterns (Schwartz, 1980) and by measures of response-location variability (Moerschbaecher, Thompson, \& Thomas, 1979). The present study is an attempt to extend the findings relating to ethanolinduced stereotypy by examining simple alternation behavior, fixed-interval (FI) rate changes, and responselocation variability.

\section{EXPERIMENT 1}

\section{Method}

Subjects. Three male albino rats from the colony at Western Washington University were used as subjects. The animals were experimentally naive and ranged in weight from 312 to $322 \mathrm{~g}$. Apparatus. The basic apparatus was a Grason-Stadler twobar operant conditioning chamber providing food reinforcement. Reinforcement programming was done using Testan modules.

Alcohol dosages. A $10 \%(\mathrm{w} / \mathrm{v})$ ethanol solution of $95 \%$ ethanol and tap water was used. Intraperitoneal (ip) injections were given in amounts of .0 (saline), $.5,1.0,1.2$, and $1.5 \mathrm{~g} / \mathrm{kg}$. A 10 -min delay was used between injections and running.

Procedure. Animals were trained in a simple left-right alternation barpressing pattern to obtain reinforcement for each correct response. A criterion of $80 \%$ correct responses (average of the two bars) was met prior to testing. Each animal was given each dosage in a different sequence in repeated treatments.

\section{Results and Discussion}

The results are shown in Figure 1. Mean number of errors are plotted for each animal for each condition (combining dosages from .5 to $1.2 \mathrm{~g} / \mathrm{kg}$ ). Sessions depicted are of 30-min duration, but an additional test of a 10-min baseline, injection with 10-min delay, and a subsequent 10-min testing period yielded comparable results.

Moderate doses of alcohol are known to enhance performance in certain tasks. For example, Reynolds and Van Sommers (1960) noted a decreased number of errors in rats leverpressing to avoid an impending shock with moderate alcohol doses, whereas higher doses impaired performance. The Reynolds and Van Sommers (1960) findings, while perhaps in keeping with a fear-reduction explanation, have been considered in light of an interference-reduction conflict theory by Brown, Mansfield, and Skurdal (1980). The theory suggests that alcohol, rather than weakening an avoidance tendency in a conflict situation, reduces the weaker of the two conflicting tendencies (whether avoidance or approach) so that the stronger is enhanced. In the event that the tendencies are of equal strength, the alcohol should have no effect (Brown et al., 1980). Thus in the Reynolds and Van Sommers' situation, the 

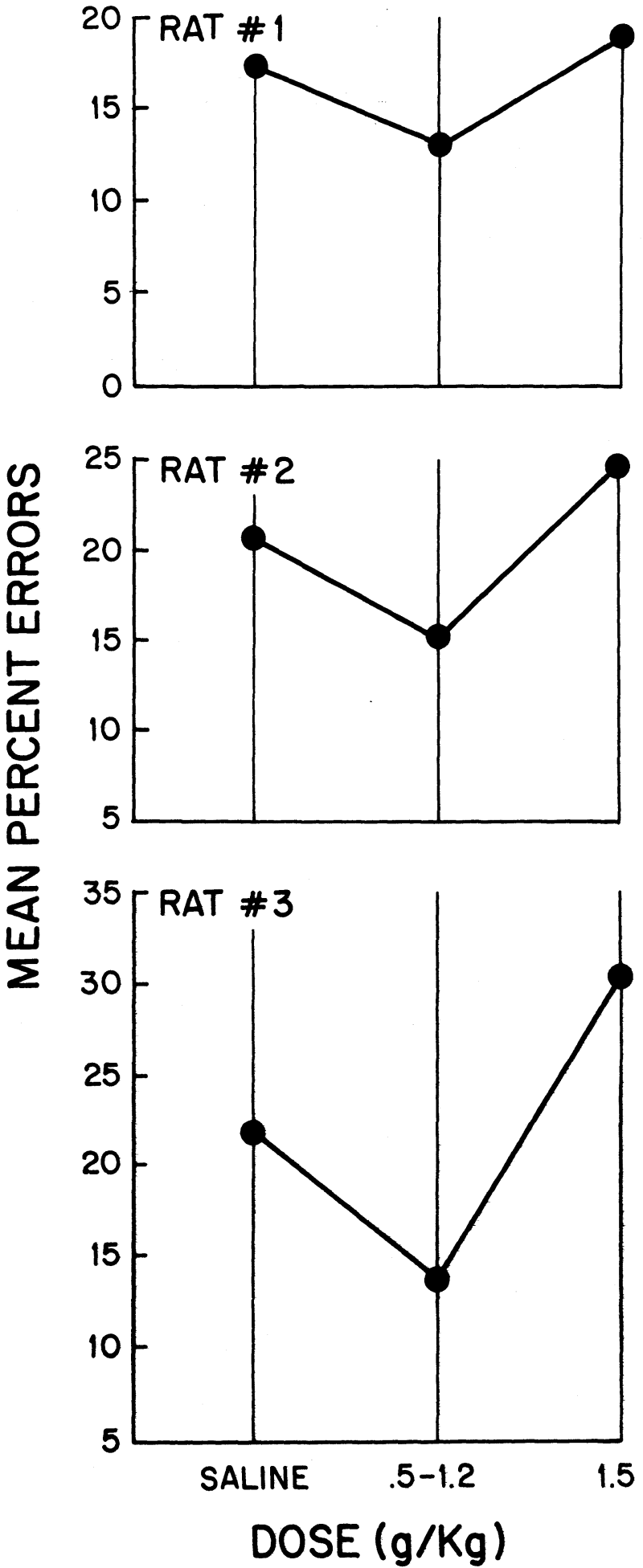

Figure 1. Mean percent errors in 30-min sessions of singlealternation barpressing as a function of ethanol dose.

relatively weak tendency to avoid the lever was further diminished by the alcohol up to those doses that produced motor impairment (Brown et al., 1980).

If the two-bar alternation responding of the present study is considered a conflict situation, the interference- reduction theory might be used to predict the facilitation of correct responding due to a reduction in the weaker tendency to produce responding errors.

\section{EXPERIMENT 2}

\section{Method}

Subjects. Eight male albino rats were used. The animals were experimentally naive and ranged in weight from 315 to $387 \mathrm{~g}$.

Apparatus. Four Gerbrands water reinforcement operant conditioning chambers were programmed to deliver rewards on an FI schedule. Running counts were made of number of responses in each 5 -sec segment of an FI 10-sec reinforcement schedule.

Dosages. A $23.75 \%(\mathrm{v} / \mathrm{v})$ ethanol solution was made with 95\% alcohol and tap water and injected ip in an amount that was $1 \mathrm{~g} / \mathrm{kg}$. This concentration is preferred in water reinforcement situations over $10 \%(\mathrm{w} / \mathrm{v})$ solutions, as the animal is not hydrated prior to the running session.

Procedure. Animals were assigned randomly to an alcohol group or a saline control group and trained to a stable performance in the FI 10 -sec schedule of reinforcement. All rats were maintained on a $23.5 \mathrm{~h}$ water-deprivation regimen and given free access to water after each daily 30 -min operant session. Injections were given $10 \mathrm{~min}$ prior to running on test day.

\section{Results and Discussion}

Figure 2 shows the basic findings. The mean difference score between the first and second 5-sec segments of the saline-injection group was 22.95 responses/min, and that of the alcohol group was 13.38 responses/min $(p=.04, U$ test $)$. That is, the change in rate or scallop within the reinforcement interval was decreased by the alcohol treatment.

These results are in general agreement with those of Leander et al. (1976), in spite of procedural differences. Thus, the present results are consistent with a rate-dependent effect in that the inhibitory effect of alcohol upon response rate was greater in the case of

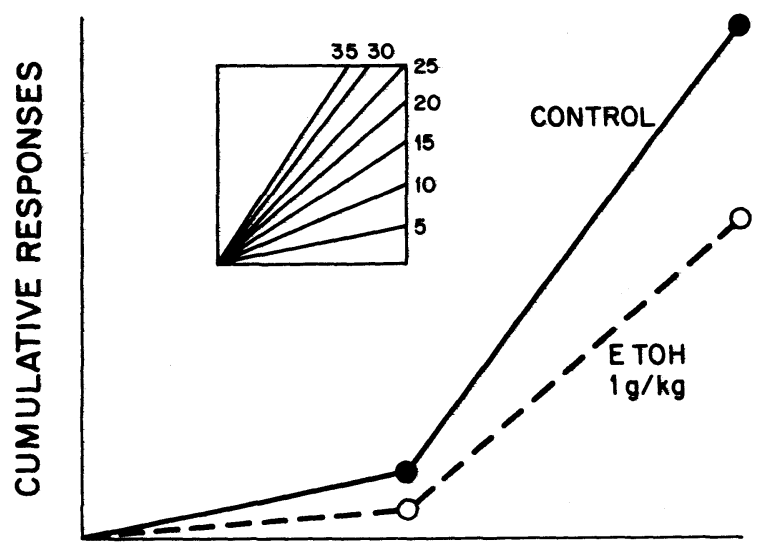

\section{F I-10 SECONDS}

Figure 2. Mean rate of responses per minute for 5 -sec segments of an FI 10-sec schedule of water reinforcement for groups treated with saline or ethanol injections. 
higher than in the case of lower responding rates, but unlike the Leander et al. findings, in which alcohol increased low rates, the rats of the present study showed little change in lower rates. Averaging over the periods of low responding rates in the present study may have missed the alcohol effects on those lowest rates immediately after the reinforcement. In any case, the present results are in keeping with the variability explanation of the rate-dependent effect (Lyon \& Robbins, 1975), as the change in rate was diminished.

\section{EXPERIMENT 3}

\section{Method}

Subjects. Ten male albino rats were used. The experimentally naive animals ranged in weight from 297 to $344 \mathrm{~g}$.

Apparatus. The two-bar operant conditioning chamber of Experiment 1 was programmed to successively reinforce either the right or the left bar with food and then to reinforce either bar with food. Under the latter condition, the number of switches from one bar to the other was counted, along with the total number of responses to each bar.

Dosages. The ethanol injection solution of $10 \%(w / v)$ was given ip in amounts of .0 (saline), 1.0 , and $1.5 \mathrm{~g} / \mathrm{kg}$. Injections were given $10 \mathrm{~min}$ prior to runs.

Procedure. Animals were trained to respond on alternate days to either the left or the right bar (cued by light) to a criterion of $80 \%$ correct responses on each bar (successive days). Then, barpressing on either bar was reinforced, and the number of switches from one bar to the other was counted in 10 -min sessions for a period of 7 days. After this training period, alcohol treatments were begun, each animal being subjected to all three dosages.

\section{Results and Discussion}

Alcohol reduced the number of switches, but it also reduced the total number of responses, so a ratio of the number of switches to the total number of responses was compared. The mean ratio for the saline control condition was .13 , for the $1.0 \mathrm{~g} / \mathrm{kg}$ dosage, .15, and for the $1.5 \mathrm{~g} / \mathrm{kg}$ dosage, .10 . There was a large withincondition variance, and no relationship appeared to exist between the measures and the alcohol treatments.

A two-bar assessment of response-location variability is not the measure commonly employed. Rather, several locations for response are generally used with a single slot. A more traditional assessment would seem necessary in order to compare alcohol effects with those of other drugs, but it is remarkable that amphetamines, the drugs most closely associated with the term stereotypy, were not found to affect response-location variability (Moerschbaecher et al., 1979).

\section{GENERAL DISCUSSION}

The present study provides additional support for a general theory of ethanol-induced stereotypy, as a single-alternation behavior appeared to become stereotyped by alcohol treatments and the responding rates within an FI schedule of reinforcement were found to be stereotyped by the alcohol treatments. The lack of an effect of alcohol upon response- location variability seems inconsistent, and, although the measure employed here differs from the standard procedure, the results are in keeping with those found using amphetamines (Moerschbaecher et al., 1979).

If, as it now appears, such distinctly acting drugs as amphetamines and alcohol share certain behavioral stereotypies, the possible basis for these changes assumes additional importance. As noted above, an element of behavioral conflict may be found in some of the tasks used to assess behavioral variability, and the theory of Brown et al. (1980) may be applied. With such an assumption, alcohol may further reduce the tendency to respond to the inappropriate bar in the alternation task, thus promoting stereotypy.

With the assumption of an inhibitory effect of alcohol on response rate and a conflict between responding or not, the interference-reduction theory may apply to the changes seen in FI performance. If the tendency not to respond is greater just after the reinforcement than before, and if alcohol reduces this lesser opposing tendency, the net tendency to respond should be less affected by alcohol (the response rate least depressed) in the period just after reinforcement than in the period just before the reinforcement. This argument could explain the results of the present study, as well as the ratedependent effect of alcohol found by Leander et al. (1976), depending upon the relative potency of alcohol depression of responding rate compared with interference reduction. In this regard, a possibility of alcohol tolerance was noted in the latter study, an event that could not have occurred in the present study's single alcohol treatment.

In addition, the interference-reduction theory fits the finding of the lack of an effect of alcohol upon two-bar responselocation variability if there were approach-approach conflicting tendencies of equal strength (Brown et al., 1980).

It is interesting to note that effects upon behavioral variability resulting from amphetamines and alcohols occur as a result of certain brain lesions. The reduction in the FI "scallop" as a result of frontal lobe lesions, for example, was noted earlier (Pribram, 1961), and other examples of response perseveration are common in the brain-lesion literature. The possibility exists that many drugs affect behavior, at least in part, by reducing variability through common central changes (Crow \& McWilliams, 1979).

\section{REFERENCE NOTE}

1. Devenport, L. D., Merriman, V. J., \& Holloway, F. A. Promotion of stereotypy by alcohol. Paper presented at the meeting of the Society for Neuroscience, Los Angeles, 1981.

\section{REFERENCES}

Brown, J. S., Mansfield, J. G., \& Skurdal, A. J. An interference-reduction theory of the effects of ethanol on conflict behavior. Physiological Psychology, 1980, 8, 423-432.

Crow, L. T., \& McWilliams, L. Relative stereotypy of wateringestive behavior induced by frontal cortical lesions in the rat. Neuropsychologia, 1979, 17, 393-400.

Crow, L. T., McWilliams, L., \& LeY, M. Relative stereotypy of water ingestive behavior induced by chronic alcohol injections in the rat. Bulletin of the Psychonomic Society, 1979, 14, 278-280.

Crow, L. T., Westveer, J. J., \& Kass, R. A. Satiety-dependent microbehaviors in water ingestion by the rat: The effects of alcohol on response duration. Physiological Psychology, 1976, 4, 163-165.

DEws, P. B. Studies on behavior IV. Stimulant actions of methamphetamine. Journal of Pharmacology and Experimental Therapeutics, 1958, 122, 137-147. 
Le ander, D. J., McMillian, D. E., \& Ellis, F. W. Ethanol and isopropanol effects on schedule controlled responding. Psychopharmacology, 1976, 47, 157-164.

Lyon, M., \& Robbins, T. The action of central nervous system stimulant drugs: A general theory concerning amphetamine effects. In W. B. Essman \& L. Valzelli (Eds.), Current developments in psychopharmacology (Vol. 2). New York: Spectrum, 1975.

Moerschbaecher, J. M., Thompson, D. M., \& Thomas, J. R. Effects of methamphetamine and scopolamine on variability of response location. Journal of the Experimental Analysis of Behavior, 1979, 32, 255-263.
Pribram, K. H. A further experimental analysis of the behavioral deficit that follows injury to the primate frontal cortex. Experimental Neurology, 1961, 3, 432-466.

Reynolds, G. S., \& Van Sommers, P. Effects of ethyl alcohol on avoidance behavior. Science, 1960, 132, 42-43.

Schwartz, B. Development of complex stereotyped behavior in pigeons. Journal of the Experimental Analysis of Behavior, 1980, 33, 153-166.

(Received for publication December 11, 1981.) 